\title{
Dyscalculia: Early predictors and practical recommendations
}

\author{
Annemie Desoete ${ }^{1,2 *}$ \\ ${ }^{1}$ Ghent University, Belgium \\ ${ }^{2}$ Artevelde University College Gent, Belgium
}

\begin{abstract}
Dyscalculia or the specific learning disorder with impairments in mathematics is a neurodevelopmental disorder causing interference with academic and occupational performance despite the provision of interventions that target those difficulties. A biological origin is the basis for behavioural signs. Studies on early predictors related to this disorder have been receiving growing attention. In this review some study outcomes on the relative importance of predictors of at-risk development in young children will be summarized.
\end{abstract}

\section{Introduction}

Mathematics is all around us. Mathematics is needed to google on the internet, use a mobile phone, travel, sort out household bills [1]. Already at the very start of formal education, individual differences exist amongst children in terms of mathematical proficiency development [2]. Children with poor mathematical skills are prone to having an elevated risk of low academic self-esteem.

Dyscalculia refers to the neurodevelopmental disorder with persisting math problems not totally accounted for a below average intelligence or lack of numerical opportunities or instruction and persisting despite the provision of interventions that target those difficulties $[3,4]$.

Mother of Bout (grade 4): 'It is quite confronting as a parent. For Bout it took until grade 2 ... before he knew when it was his birthday. I didn't think it was normal. A child knows when it is his birthday [5]."

Kristel (master's in education): "Why was elementary school like hell? Because I felt a huge pressure on me. Open your manual on page 68 . There we go again! Where is page 68 ? Other pupils already had taken down the title while I was still looking for page 68. It was a constant feeling of needing to exert myself. I have to take care that I can follow. That is what made it so hard for me. Everyone was faster than I was [5]"

The prevalence of dyscalculia is around 5-7 [3-8]. There is also an increased prevalence of dyscalculia in children with ADHD [3,9] and DCD $[3,10]$. Moreover, dyscalculia is reported in relation to the Fragile X-syndrome, the developmental Gerstman Syndrome, the Turner Syndrome, the Shprintzen syndrome, phenylketonuria or neurofibromatosis type $\mathrm{A}$ and the Klinefelter syndrome or disease of Duchenne [9]. In addition there is often comorbidity with an impairment in spelling accuracy and severe difficulties with grammar and punctuation accuracy $[3,10]$.

\section{Predictors}

Although the severe underachievement and persistent math difficulties become fully manifest in elementary school, there are some kindergarten predictors that might be important to recognize in a pediatric consult. In what follows the findings on these predictors will be reviewed.
Dyscalculia aggregates in families. The relative risk of dyscalculia is substantially higher in fist-degree relatives of individuals with learning difficulties compared with those without them. The prevalence in siblings ranges from 40 to $64 \%[1,6,8,9]$. In addition, prematurity and very low birth weight was found to increase the risk for specific learning disorders [6].

The importance of the 'estimation of quantities' as predictor was confirmed, revealing that children with dyscalculia had severe problems with number representation (assessed with a magnitude comparison task) in kindergarten [10-14]. The combination of number representation and symbolic (Arabic numbers and number words) deficits in kindergarten was a predictive indicator for developing dyscalculia in elementary school [10-14]. Children with dyscalculia seem to encounter already severe problems with magnitude comparison and estimation abilities in kindergarten [10-15]. Also counting in kindergarten was an important indicator for dyscalculia. A three-year longitudinal study $[1,8,10]$ on 471 children followed up from kindergarten (at age 4 to 5 years) to grade 2 (at age 7 to 8 years), revealed that $87.50 \%$ of the children could be correctly diagnosed in kindergarten by a combination of the procedural and conceptual prerequisite knowledge of counting and number representation. proficiency 'Procedural counting knowledge' was defined as children's ability to perform a counting task, for example, a child succeeds in determining that there are five objects in an array. 'Conceptual counting knowledge' was described as a child's understanding of the essential counting principles: the stable order principle, the one-onecorrespondence principle and the cardinality principle. However, it seemed to be easier to screen the children who are not at risk than to detect the at-risk for dyscalculia based on their kindergarten abilities $[1,8,10]$. Nevertheless, based on clinical cut off scores (provided by test

${ }^{\star}$ Correspondence to: Annemie Desoete, Ghent University, Belgium, E-mail: Annemie.Desoete@UGent.be

Key words: dyscalculia, counting, language, seriation, classification

Received: March 18, 2019; Accepted: March 22, 2019; Published: March 27, 2019 
publishers norm tables) we could predict four out of five children with dyscalculia in grade 1 and 2 based on number comparison, conceptual counting and procedural counting scores in kindergarten [10].

In addition, also language revealed to be an indicator for dyscalculia, since the variance in mathematical proficiency in kindergarten was predicted by language on top of the counting knowledge as indicator $[10,11]$, Language demands of mathematics should not be overlooked $[4,12]$. Different language components might contribute to different mathematical skills, with expressive language and language structure in kindergarten as predictive indicators for mathematical abilities later on [10].

Finally, seriation and classification were also predictive indicators for dyscalculia. Seriation (or the logical ability to sort objects based on differences while ignoring similarities) and classification (or the logical ability to sort objects based on similarities, while ignoring differences) abilities had some value added in the screening of dyscalculia in kindergarten. Thus, although several neo-Piagetian researchers question the causality of seriation and classification for understanding number, children adequately solving seriation and classification tasks in kindergarten perform better in mathematical tasks in the first grades of elementary school [9].

\section{Conclusion}

Studies revealed that dyscalculia has a high heritability and that prematurity and very low birth weight increases the risk for dyscalculia. In addition, dyscalculia is frequently but not invariably preceded in kindergarten by delays in language and impaired (procedural and conceptual) knowledge of counting, seriation, classification and estimation of quantities. A comprehensive pediatric assessment will involve a multidisciplinary diagnosis and professionals with expertise in learning disorders. Dyscalculia as potential diagnosis should be included when other neurodevelopmental (e.g. AHDH, DCD, dyslexia and especially severe spelling disorders) co-occur.

\section{References}

1. Budd CJ (2015) Promoting maths to the general public. In: Kadosh RC, Dowker A (Eds) The oxford handbook of numerical cognition. Oxford UK: Oxford university press: 3-16.

2. Claessens A, Engel M (2013) How important is where you start? Early mathematics knowledge and later school success. Teachers College Record 115: 060306.

3. Desoete A, Baten E (2017) Indicators for a specific learning disorder in mathematics or dyscalculia in toddlers and in kindergarten children. Belgian Journal of Paedicatrics 19: $122-124$.

4. Geary DC (2015) Preschool children's quantitative knowledge and long-term risk for functional innumeracy. In: Chinn S (ed) The International Handbook for Mathematical difficulties and Dyscalculia. London and New York: Routledge: 235-242.

5. Desoete A (2014) Cognitive predictors of mathematical abilities and disabilities. In: Kadosh RC, Dowker A (eds) The Oxford handbook of mathematical cognition. Oxford: Medicine UK: 899-914.

6. American Psychiatric Association (2013) Diagnostic and statistical manual of mental disorders ( $5^{\text {th }}$ ed.). Washington DC: APA 2013: 66-74.

7. Barbaresi WJ, Katusic SK, Colligan RC, Weaver AL, Jacobsen SJ (2005) Learning disorder: Incidence in a population-based birth cohort, 1976-82, Rochester, Minn. Ambul Pediatr 5: 281-289. [Crossref]

8. Shalev R, Manor O, Kerem B, Ayali M, Badichi N, et al. (2001) Developmenta dyscalculia is a familial learning disability. J Learning Disabil 34: 59-65. [Crossref]

9. Desoete A, Praet M, Titeca D, Ceulemans A (2013) Cognitive phenotype of mathematical learning disabilities: What can we learn from siblings? Res Dev Disabil 34: 404-412. [Crossref]

10. Stock P, Desoete A, Roeyers H (2009) Screening for mathematical disabilities in kindergarten. Dev Neurohab 12: 389-396. [Crossref]

11. Stock P, Desoete A, Roeyers H (2010) Detecting children with arithmetic disabilities from kindergarten: Evidence form a three-year longitudinal study on the role of preparatory arithmetic abilities. J Learning Disabil 43: 250-268.

12. Desoete A (2015) Predictive indicators for mathematical learning disabilities/ dyscalculia in kindergarten children In: Chinn S (ed) The International Handbook for Mathematical difficulties and Dyscalculia. London and New York: Routledge 90-100.

13. Praet M, Titeca D, Ceulemans D, Desoete A (2013) Language in the prediction of arithmetics in kindergarten and grade 1. Learning Indiv Diff 27: 90-96.

14. Desoete A, Ceulemans A, De Weerdt F, Pieters S (2012) Can we predict mathematica learning disabilities from symbolic and non-symbolic comparison tasks in kindergarten? British J Educat Psychol 82: 64-81. [Crossref]

15. Desoete A (2017) Dyscalculia: Whats in a Name? Open Access J Sci 1: 00021.

Copyright: (C2019 Desoete A. This is an open-access article distributed under the terms of the Creative Commons Attribution License, which permits unrestricted use, distribution, and reproduction in any medium, provided the original author and source are credited. 